\title{
The application of Wing-In-Ground-Effect (WIG) as a more cost effective transportation in the Indonesian archipelago
}

\author{
Prasetyo Edi \\ Program Studi Teknik Dirgantara Sekolah Tinggi Teknologi Adisutjipto \\ Email: prasetyoedi@stta.ac.id
}

\begin{abstract}
Current trends in the design of transport aircraft have shown that in order to be economically viable and competitive it is necessary to investigate technologies that can give an improvement in performance and operational flexibility goal, but must be shown to be cost effective. The current competitive environment forces the potential customers to buy advanced technology aircraft and requires manufacturers to provide more operational flexibility, without drastic performance penalties. This is a challenging task, which might be solved by the use of new technologies. It is believed that the application of a WIG (Wing-in-Ground-Effect) would assist in achieving such a task. This paper describes an investigation aimed to examine the suitability of a WIG concept as a more cost effective transportation in the Indonesian archipelago. This work is unique in terms of application in the Indonesian archipelago. The paper describes the phenomenon of WIG and outlines the benefits and penalties of WIG. It then discusses the possibility of the application of WIG to NKRI. It concludes with a discussion of the results and recommendations for future work.
\end{abstract}

Keywords: WIG (Wing-in-Ground-Effect), Aircraft Design, High Speed Marine Transportation.

\section{Pendahuluan}

NKRI adalah merupakan negara kepulauan yang mempunyai pulau kurang lebih berjumlah 17.508 [1], termasuk diantaranya lima pulau besar (Irian-Jaya, Kalimantan, Sumatra, Sulawesi dan Jawa). Negara kepulauan dengan kata lain negara yang wilayahnya terdiri dari pulau-pulau yang dihubungkan (bukan dipisahkan) oleh laut (negara maritime), hal ini bisa dilihat pada gambar 1. Untuk lebih mempersatukan pulau-pulau didalam NKRI, Indonesia harus menguasai laut, udara serta perangkat komunikasi. Sehubungan dengan makalah ini, WIG dapat dijadikan salah satu wahana penghubung/pemersatu pulaupulau didalam NKRI.

Negara Indonesia juga memiliki sungai yang besar dan panjang, terutama di lima pulau besarnya [2 dan 3]. Berikut adalah 5 sungai yang terpanjang di NKRI : 
1. Sungai Kapuas (kedalaman/lebar $6 \mathrm{~m} / 450 \mathrm{~m}$ ), diperlihatkan di gambar 2, total panjang sungai Kapuas mencapai 1.143 kilometer. Sungai Kapuas dimulai dari Pegunungan Muller hingga Selat Karimata (Laut China).

2. Sungai Mahakam memiliki panjang 920 kilometer yang berada di Provinsi Kalimantan Timur bermuara di Selat Makasar.

3. Sungai Barito (kedalaman/lebar $6 \mathrm{~m}-14 \mathrm{~m} / 350 \mathrm{~m}-500 \mathrm{~m}$ ) mengalir dari Kalimantan Tengah hingga Kalimantan Selatan. Panjang Sungai Barito mencapai 890 kilometer.

4. Sungai Batanghari berada di Kabupaten Solok, Sumatera Barat dan mengalir hingga Jambi. Sungai ini mengalirkan air dari Gunung Rasan sampai Laut China Selatan. Sungai tersebut memiliki panjang mencapai 800 kilometer. Sebagian area Sungai Batanghari termasuk dalam kawasan Taman Kerinci Seblat.

5. Sungai Musi memiliki panjang 750 kilometer dan berada di Sumatera Selatan. Sungai tersebut mengalirkan air dari mata air di kawasan Kepahiang (Bengkulu) hingga ke Selat Bangka. Sungai ini membelah Kota Palembang menjadi dua wilayah. Sehingga dibangun Jembatan Ampera yang menghubungkan dua wilayah tersebut

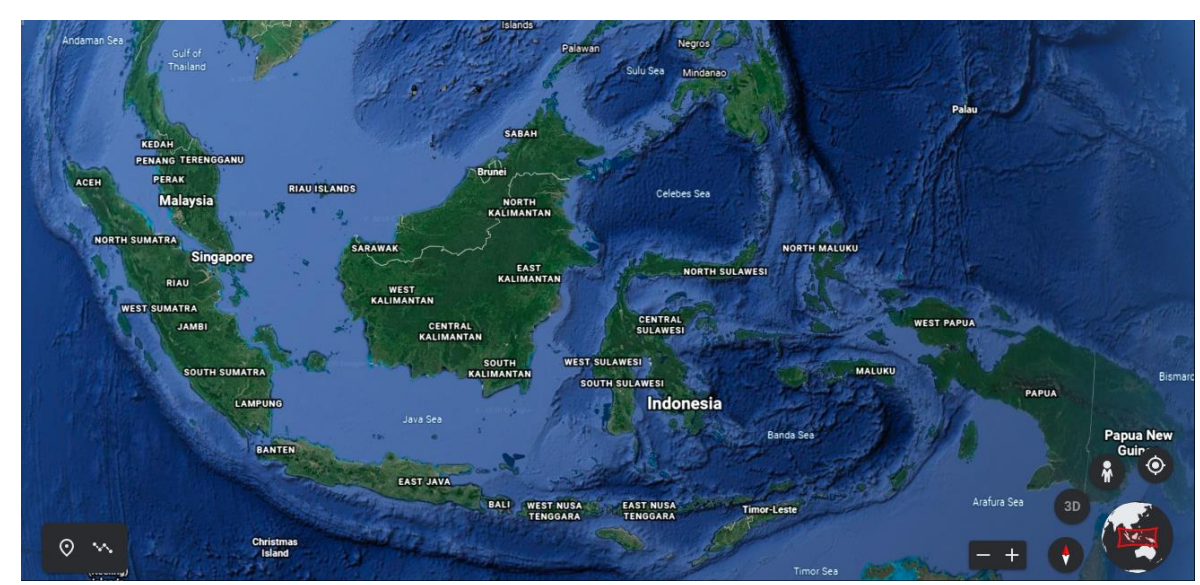

Gambar 1. Negara Kepulauan Indonesia

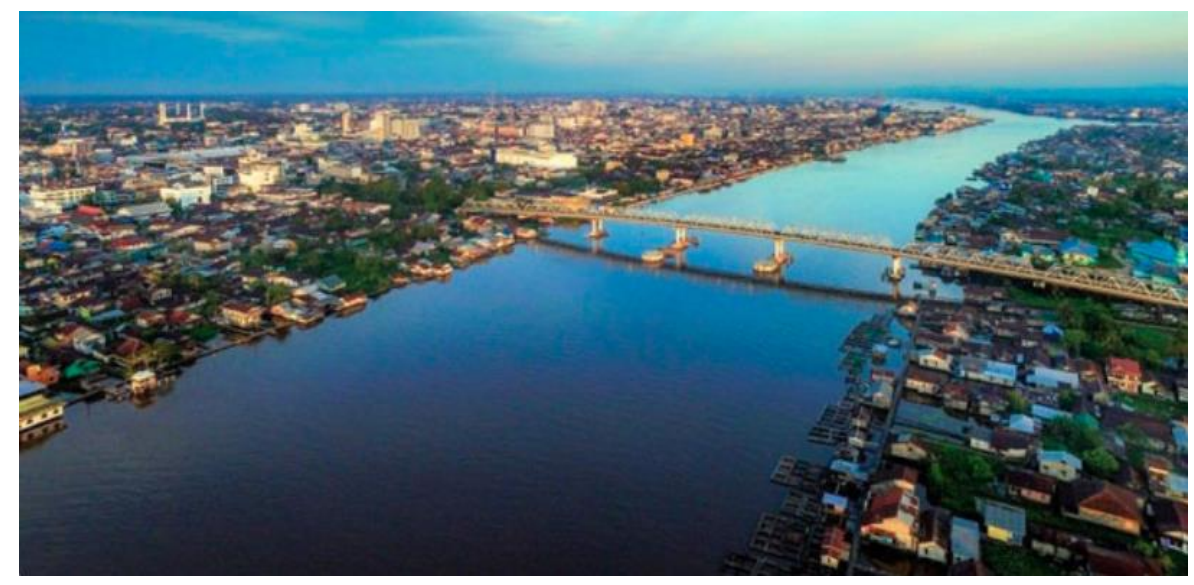

Gambar 2. Sungai Kapuas menjadi urat nadi di Kalimantan Barat

Di daerah dimana alat transportasi (moda transportasi beserta infra struktur penunjangnya) masih mahal (seperti kebanyakan diluar pulau Jawa), WIG bisa dijadikan salah satu solusi untuk mendapatkan moda 
transportasi yang lebih efisien. Selain laut dan sungai, negara Indonesia juga memiliki danau maupun bendungan yang besar. Dalam hal ini WIG bisa dijadikan moda transportasi, sarana berolah-raga dan hiburan yang lebih optimal. Pengadaan pesawat latih (untuk calon penerbang/pilot, mahasiswa/i penerbangan) beserta piranti pendukungnya tergolong mahal, karena hargannya yang relative lebih murah, untuk mengatasi hal ini WIG dapat dijadikan salah satu pilihan yang cukup menguntungkan. Untuk mendapatkan analisa yang lebih akurat dalam merancang pesawat terbang biasanya diperlukan laboratorium uji terbang beserta piranti pendukungnya yang tergolong cukup mahal. WIG dapat menjadi alternatif pilihan dikarenakan ongkos pembuatannya yang relative lebih mudah dan murah tetapi dapat menghasilkan analisa yang bisa dipertanggung jawabkan.

\section{Moda Transportasi Air/Laut}

Berbagai moda transportasi air/laut yang dapat dijadikan pilihan seperti diperlihatkan di gambar 3 (airboat, hovercraft, hydrofoil dan WIG). Dari keempat moda transportasi air/laut tersebut yang relative lebih cepat adalah WIG, ini dikarenakan pada saat terbang tidak ada bagian WIG yang bersentuhan dengan air, yang mana gaya hambatan WIG dengan air lebih besar dari pada gaya hambatan WIG dengan udara.
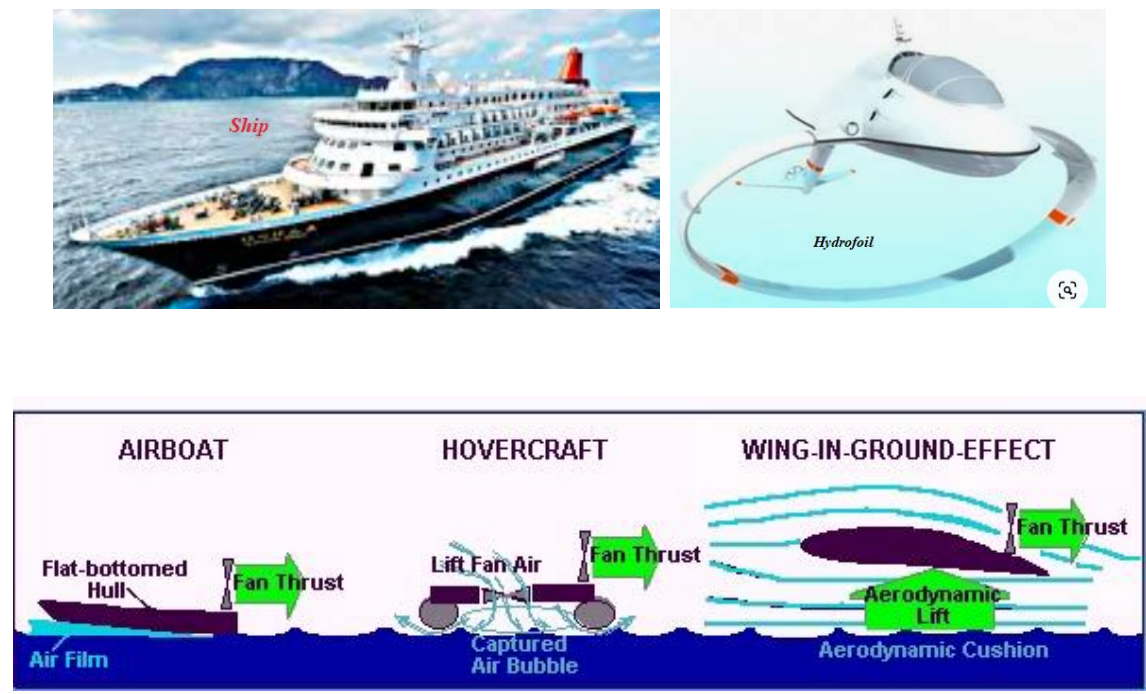

Gambar 3. Moda Transportasi Air/Laut.

\section{WIG (Wing-in-Ground-Effect)}

WIG adalah kendaraan berkecepatan tinggi yang dirancang untuk dapat terbang berkelanjutan di atas permukaan yang relatif datar (biasanya di atas laut, danau, atau sungai) dengan memanfaatkan groundeffect, interaksi aerodinamis antara sayap dan permukaan [4]. Pada pesawat bersayap tetap, ground-effect adalah peningkatan gaya angkat (lift) dan penurunan gaya hambat aerodinamis (drag) yang dihasilkan sayap pesawat saat terbang mendekati permukaan tetap, sehingga meningkatkan rasio (L / D). Berdasarkan kemampuan terbangnya, IMO (International Maritime Organization) mengklasifikasi WIG kedalam beberapa klas seperti yang ditunjukkan oleh gambar 4 [5]. 


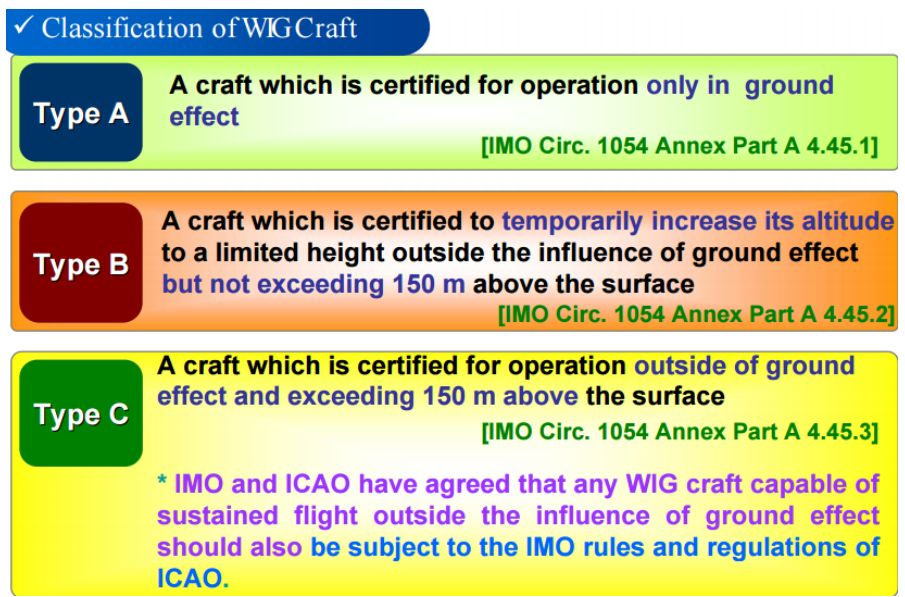

Gambar 4. Klasifikasi WIG oleh IMO.

\subsection{Aerodinamika WIG}

Bagaimana airfoil dapat menghasilkan gaya angkat (lift) dapat dijelaskan dengan hukum Bernoulli (persamaan - 1) maupun dengan teori Kutta-Joukowski (persamaan - 2)[6 dan 7].

$$
p+\frac{1}{2} \rho V^{2}+\rho g z=C
$$

Lift/wing-span $=\mathrm{L} / \mathrm{b}=L^{\prime}=\rho V \Gamma$

Lift = gaya angkat $=\quad L=\left(0,5 \rho V^{2} S\right)\left(C_{L_{\alpha}}\left(\alpha-\alpha_{0}\right)\right)$

Lift curve slope $=\quad C_{L_{\alpha}}=\frac{a_{0}}{1+\left(a_{0} / \pi A R\right)(1+\tau)} \quad A R=b^{2} / S$

Drag $=D=\left(0,5 \rho V^{2} S\right)\left(C_{D_{0}}+\phi C_{L}^{2} /(\pi e A R)\right) \quad \phi=(16 h / b)^{2} /\left(1+(16 h / b)^{2}\right)$

Pada gambar 5 ditunjukkan aliran udara disekitar airfoil (2D-flow), sedangkan gambar 6 menunjukkan aliran udara disekitar wing (3D-flow).

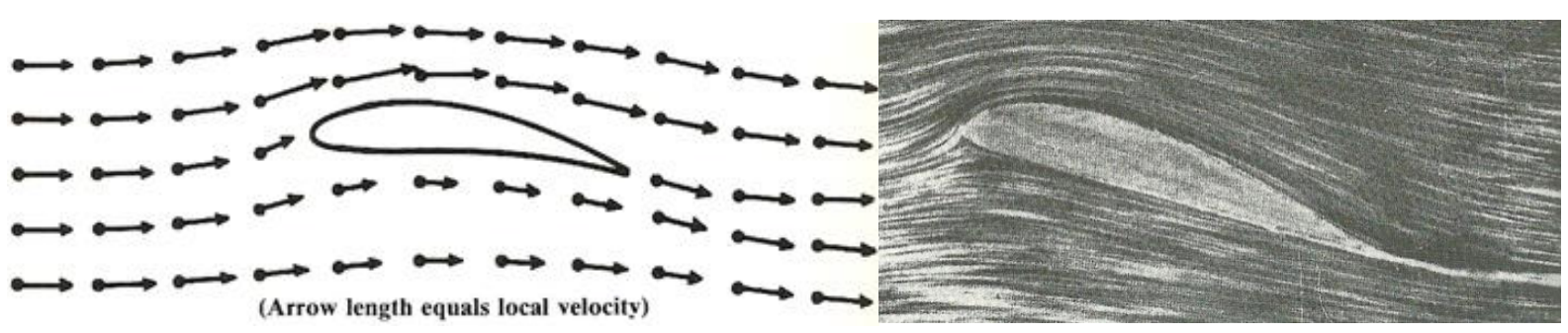

Gambar 5. Aliran Udara di Sekitar Airfoil (2D-flow). 

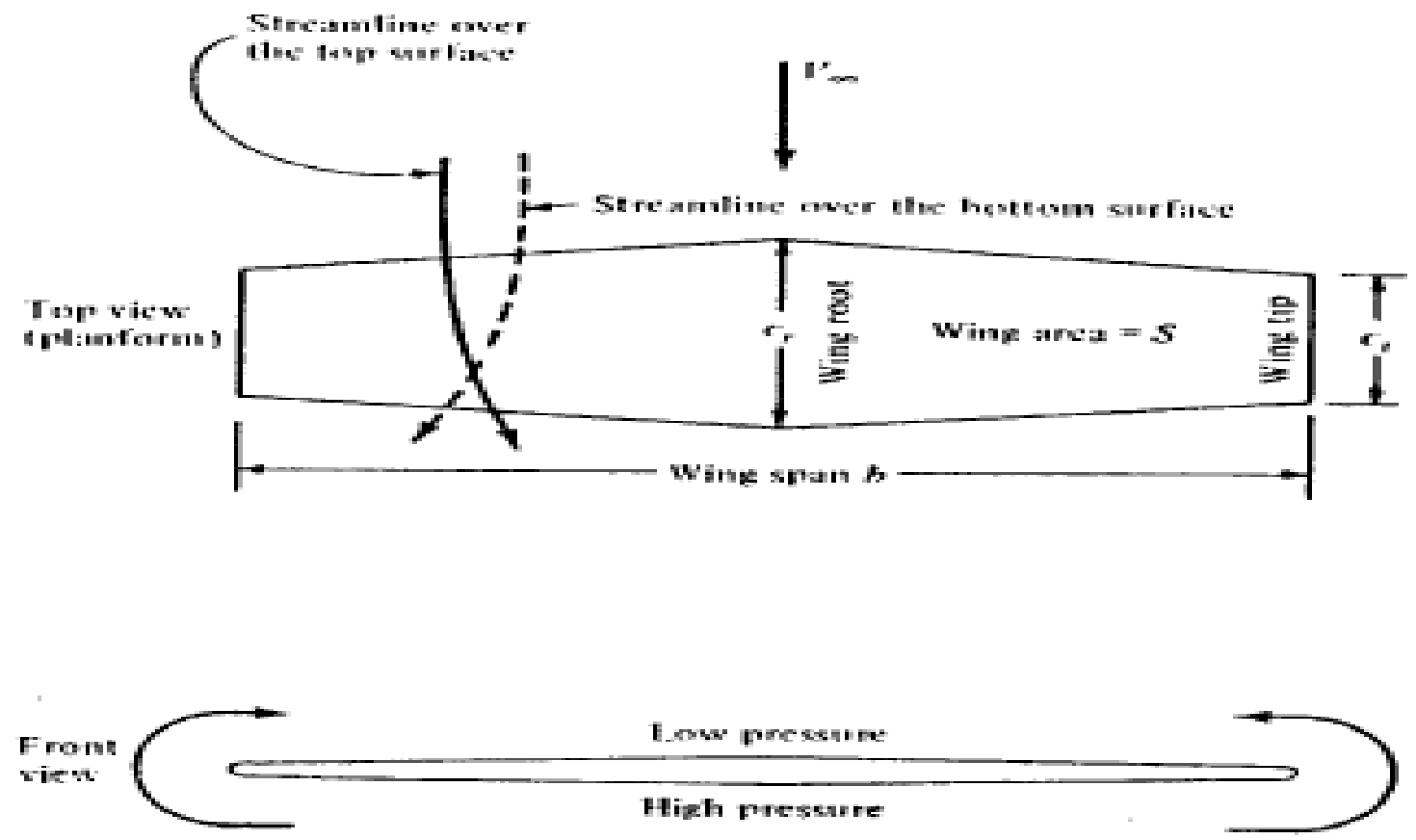

Gambar 6. Aliran Udara di Sekitar Wing (3D-flow).

\section{Comparison between inside and outside WIG zone}

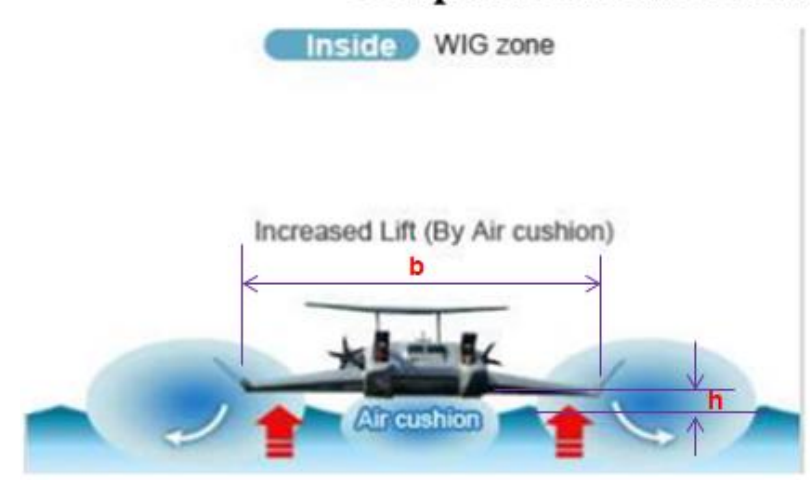

\section{Operation inside WIG zone}

The air cushion which generated between the wing and the ground is acting as the force to lift up the wing. In addition, this effect reduces the drag of the vortex which is occurred at the wing tip.

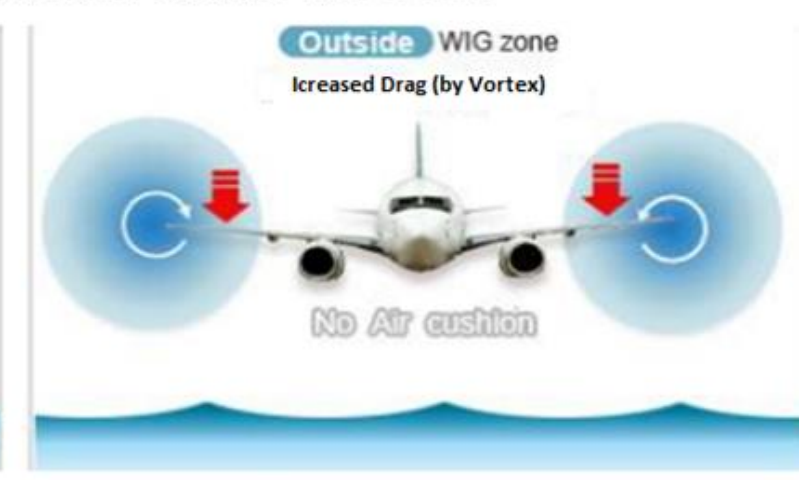

\section{Operation outside WIG zone}

The energy generated under the wing vanishes into space meaninglessly. And the vortex generated at the tip of the wing presses the upper part of the wing again and thus efficiency decreases.

Gambar 7. WIG vs non-WIG

Jika WIG terbang dekat dengan permukaan (Wing-in-Ground-Effect), maka akan terjadi interaksi aerodinamik antara wing dan permukaan, yang mana interaksi ini akan membentuk bantalan udara (air 
cushion, terlihat pada gambar 7) yang pada akhirnya akan menambah gaya angkat pada wing; efek ini juga akan mengurangi kekuatan tip-vortex yang pada akhirnya akan mengurangi gaya hambatan (drag), sehingga secara keseluruhan Wing-in-Ground-Effect akan menambah (L/D) ratio (gambar 8). Dapat juga dikatakan bahwa Wing-in-Ground-Effect akan menambah ektifitas bentangan sayap ( $\mathrm{b}=$ wing span), sehingga hal ini menurut persamaan 3 dan 4 akan menambah lift dan juga akan mengurangi drag (persamaan 5).

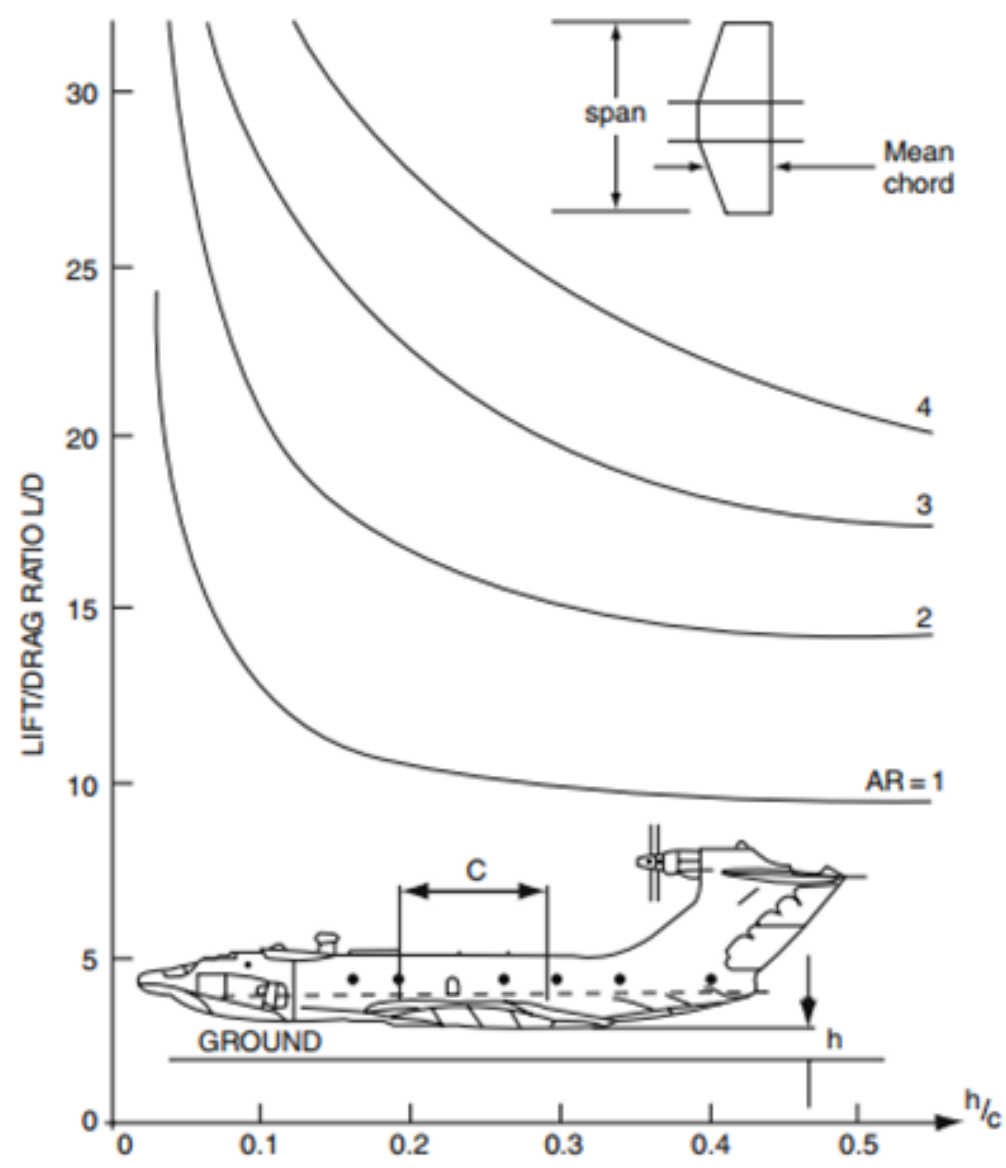

Gambar 8. WIG : L/D vs h/c

\subsection{Keuntungan dan kerugian WIG}

Diantara keuntungan WIG adalah seperti disebutkan dibawah ini :

- Lift/Drag ratio yang relative lebih tinggi

- Pemakaian bahan bakar lebih irit, WIG dapat memakai mesin mobil

- Lebih ramah lingkungan

- Pengendraan yang lebi nyaman

- WIG lebih cepat dari kapal laut $(420 \mathrm{~km} / \mathrm{h})$

- WIG lebih murah dari pada pesawat terbang

- Terbang pada ketinggian yang rendah akan sulit dideteksi oleh radar

- Biaya perawatan yang lebih murah ( seperti mobil)

- WIG dikategoirikan sebagai "maritime vessels" untuk construction, insurance, operator licensing dan registration requirements.

- Tidak memerlukan sertifikasi yang komplek 
- Untuk mengoperasikan WIG tidak diperlukan "pilot license"

- Untuk pemeliharaannya tidak diperlukan "certified aircraft mechanic"

- Tidak memerlukan landas pacu beserta infra struktur penunjangnya yang mahal

- Jika ada kerusakan, WIG tinggal mendarat di air dengan mudah dan aman

- Untuk manufacturer, WIG merupakan kesempatan emas karena hanya ada sedikit pemain di pasar.

Diantara kerugian WIG adalah seperti disebutkan dibawah ini :

- Diperlukan power yang lebih besar untuk tinggal landas dikarenakan gaya hambatan dari air yang relative lebih tinggi, sehingga ada kemungkinan daya berlebih yang tidag berguna pada saat terbang di udara

- Sifat air laut yang korosif

Teknik2 dibawah ini dapat dipakai untuk memperpendek panjang tinggal landas, diantaranya adalah :

a. Dengan memakai hydroski gear, seperti yang terlihat di gambar 9 .

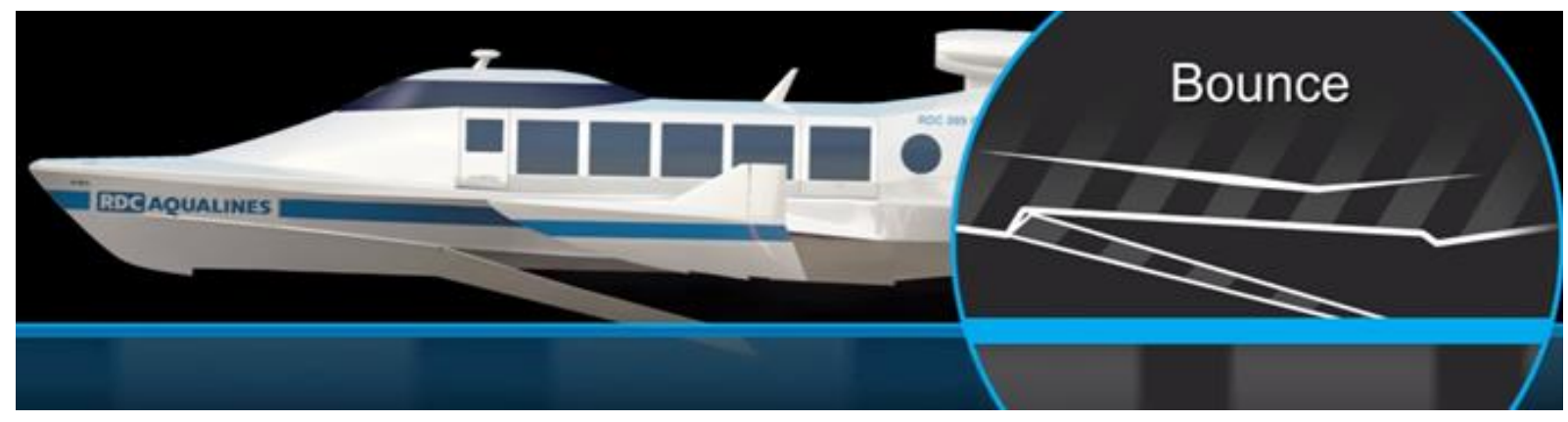

Gambar 9. WIG dengan Hydroski Gear

b. Dengan memakai bantalan udara sementara dibawah badan/sayap WIG, seperti yang terlihat di gambar 10.
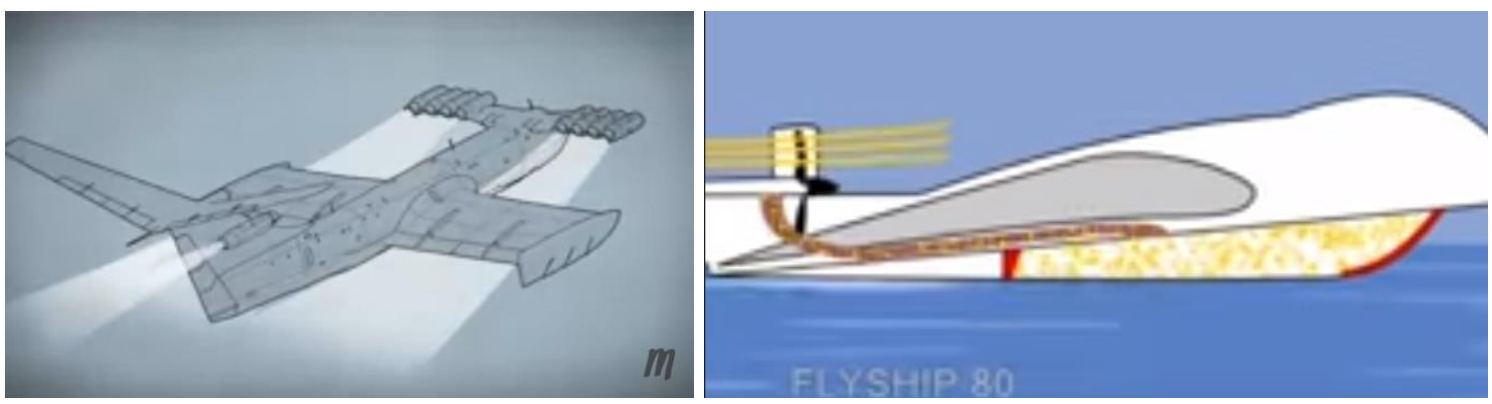

Gambar 10. WIG dengan Bantalan Udara Sementara 
3.3. Beberapa Kemungkinan Pemakaian WIG di NKRI.

Beberapa kemungkinan pemakaian WIG di NKRI adalah seperti disebutkan dibawah ini :

- Pemakaian WIG di perusahaan minyak dan gas

- Untuk keperluan pribadi : sport, rekreasi/hiburan, dll.

- Taksi air

- Ferry

- Pesawat kargo

- Pesawat penyelamat untuk crew dan penumpang dari pesawat/kapal/floating excavator/submarine yang mengalami kerusakan

- Alat transportasi untuk rescuers/rescue tools/materials ke tempat kecelakaan

- Kerja awal untuk pencegahan kerusakan ekologi akibat tumpahan minyak di laut

- Pemantau ekologi

- Penjaga daerah konservasi

- Penunjang aktifitas Polisi

- Global sea safety system

- Sebagai wahana pendukung untuk R\&D kelautan

- Riset \& pengembangan di bidang "high speed marine transportation"

\section{Kesimpulan}

Berdasarkan uraian diatas WIG sangat diperlukan sekali oleh NKRI tidak hanya sebagai alat pemersatu bangsa dan negara bahkan juga dapat dijadikan untuk menunjang ketahanan sosial, ekonomi, politik dan hankam. Pemerintah diharapkan dapat segera mulai untuk mengaktifkan lembaga2 riset dan manufaktur untuk persiapan pengembangan WIG. Mari kita rebut kembali kajayaan di laut (Jalesveva Jayamahe $=$ di lautan kita jaya) seperti yang sudah dirintis oleh para founding father.

\section{Ucapan Terimakasih}

Ucapan terimakasih penulis sampaikan kepada Program Studi Teknik Dirgantara - STT Adisutjipto yang telah berperan dalam memberikan semangat serta kesempatan kepada penulis untuk berpartisipasi didalam SENATIK ini.

\section{Daftar Pustaka}

[1] Coordinating Ministry for Maritime and Investments Affairs (Indonesia), https://en.wikipedia.org/wiki/Coordinating_Ministry_for_Maritime_and_Investments_Affairs_(Indo nesia), Desember 2020.

[2] https://www.kompas.com/skola/read/2020/01/11/210000569/5-sungai-terpanjang-diindonesia?page=all, 1/11/2020.

[3] https://kalteng.bps.go.id/statictable/2016/09/21/261/nama-nama-sungai-menurut-panjangkedalaman-dan-lebar-di-provinsi-kalimantan-tengah.html, 11/5/2020.

[4] Darrol Stinton, The Anatomy of the Airplane, BSP Professional Books, 2nd ed., 1997, Oxford, UK.

[5] IMO (International Maritime Organization). Introduction to IMO : Classification of WIG. https://www.imo.org/en/About/Pages/Default.aspx.

[6] John D. Anderson Jr., Fundamentals of Aerodynamics, 5th Edition, McGraw Hill, 2011.

[7] Daniel P. Raymer, Aircraft Design: A conceptual approach, AIAA Education Series, 4th edition, 2006. 